Letrônica, Porto Alegre, v. 7, n. 2, p. 569-587, jul./dez., 2014

\title{
A PRODUÇÃO ORAL DAS OCLUSIVAS DE FALANTES BILÍNGUES HUNSRIQUEANO-PORTUGUÊS NA LEITURA DO PORTUGUÊS
}

\author{
THE ORAL PRODUCTION OF PLOSIVES PRODUCED BY BILINGUAL SPEAKERS \\ (HUNSRÜCKISCH-PORTUGUESE) IN THE READING OF PORTUGUESE
}

Sabrina Gewehr-Borella*

\begin{abstract}
Resumo: 0 presente trabalho analisa as transferências fonético-fonológicas do hunsriqueano para o português, no que diz respeito à sonoridade das oclusivas. Para tanto, são analisados excertos de leituras em português da 'Parábola do Filho Pródigo', retirados do banco de dados do Projeto Alma-H (Atlas Linguístico-Contatual das Minorias Alemãs na Bacia do Prata: Hunsrückisch), produzidos por informantes de 6 pontos de pesquisa, divididos em dois grupos sociais (classe baixa e classe alta) e duas faixas etárias (geração I e II). Objetiva-se a partir de tais dados: a) investigar a incidência da ocorrência de transferências em cada uma das oclusivas; b) comparar as transferências interlinguísticas encontradas com as regras de vozeamento do hunsriqueano, descritas por Altenhofen (1996), com relação à tonicidade das sílabas e, finalmente, c) verificar de que modo as diferentes dimensões (diatópica, diastrática, diageracional) sugeridas pelo modelo teórico da dialetologia pluridimensional (THUN, 1998, 2010) atuam na variação de sonoridade encontrada nos dados analisados. Os resultados apresentados permitem um melhor entendimento dos processos de transferência interlinguística entre o hunsriqueano e o português, o que contribui para a descrição da variedade do português falada nas regiões pesquisadas.
\end{abstract}

Palavras-chave: Bilinguismo hunsriqueano-português; Transferência fonético-fonológica; Leitura.

\begin{abstract}
The current study analyzes the phonetic-phonological transfers from Hunsrückisch into Portuguese, related to the sonority of the plosives. To this end, readings of the 'Parable of the Prodigal Son', written in Portuguese and collected from the Alma-H Project (Contatual-Linguistic Atlas of German Minorities in the 'Bacia do Prata'Hunsrückisch), are analyzed. The data produced by informants of six research places, are divided into two social groups (low class and high class) and two different ages (generation I and II). The goals of this study are: a) investigate the numbers of transfers in each one of the plosives; b) compare the interlinguistic transfers found with the Hunsrückisch voicing rules, described by Altenhofen (1996), and related to the tonicity of the syllables, and finally, c) check how the different dimensions (diatopic, diastratic, diagenerational), suggested by the theoretical model of pluridimensional dialectology (THUN, 1998, 2010), act in the variety of sonority found into the data analyzed. The results shown allowed us to understand the interlinguistic transfers processes between Hunsrückisch and Portuguese, which contribute to the description of the variety of Portuguese spoken in the regions researched to this study. Keywords: Hunsrückisch-Portuguese bilingualism; Phonetic-phonological transfers; Reading.
\end{abstract}

\footnotetext{
* Mestre em Letras pela Universidade Católica de Pelotas (UCPEL). Doutora em Letras da Universidade Federal do Rio Grande do Sul (UFRGS). Bolsista CAPES.
} 


\section{Introdução}

A língua de imigração hunsriqueana, também denominada de Hunsrückisch, foi introduzida no Brasil a partir da chegada dos primeiros imigrantes alemães em 25 de julho de 1824. Mesmo depois de decorridos 190 anos desde a chegada dos primeiros imigrantes, o hunsriqueano ainda é falado nos dias atuais por cerca de 500.000 pessoas só no Rio Grande do Sul (cf. ALTENHOFEN et al., 2008). Essa língua de imigração, bastante difundida também nos estados de Santa Catarina e Paraná, no Paraguai e na Argentina, não ficou restrita ao sul, tendo falantes atualmente também no Mato Grosso e até mesmo no Pará (cf. informações do Projeto Alma-H²).

A língua atual, evidentemente, não é a mesma trazida pelos primeiros imigrantes. Objetos e elementos da fauna e da flora, desconhecidos na Alemanha, são apenas alguns exemplos de um novo vocabulário que foi sendo aos poucos acrescido à fala dos colonos. O vocábulo 'funda', por exemplo, foi agregado ao hunsriqueano como [fund]], incorporando à palavra por aqui falada uma característica bastante comum no alemão e ausente no português: a finalização de coda com consoante oclusiva.

O contato com os moradores da nova pátria fez com que os imigrantes aprendessem a língua portuguesa. Características fonético-fonológicas do hunsriqueano foram transferidas nessa aprendizagem, gerando palavras com oclusivas fora dos padrões do português. Nos dias atuais, verifica-se que este tipo de transferência vem diminuindo, devido a uma série de fatores. Apesar de ser ainda comum em ambientes de contato linguístico, esse tipo de transferência continua sendo bastante estigmatizado.

As transferências fonético-fonológicas (fala) e grafo-fônico-fonológicas (escrita) são chamadas comumente, no domínio público, de "troca de letras". Tais transferências foram analisadas na minha dissertação de mestrado (GEWEHR-BORELLA, 2010), onde constatei, na análise das oclusivas do português, que crianças bilíngues (hunsriqueanoportuguês) apresentam um padrão de VOT (Voice Onset Time) distinto do português com

\footnotetext{
2 Projeto Alma-H. O Atlas Linguístico-Contatual das Minorias Alemãs na Bacia do Prata - Hunsrückisch (ALMA-H) é um macroprojeto desenvolvido em conjunto pelas áreas de Romanística (da ChristianAlbrechts-Universität de Kiel, Alemanha) e Germanística (do Instituto de Letras da Universidade Federal do Rio Grande do Sul, Brasil), sob a coordenação de Harald Thun (Kiel) e Cléo V. Altenhofen (Porto Alegre). Informação retirada da página do Projeto Alma-H em 18/05/2013. Para maiores informações ver: http://www.ufrgs.br/projalma.
} 
muito mais frequência do que crianças monolíngues (português). Pode-se citar como exemplo a palavra 'bico' que foi produzida, diversas vezes, dentro da 'categoria zero de VOT', ao ser pronunciada como [p]ico ou [b] foram produzidas distintamente dos padrões do português, as outras oclusivas sonoras seguiram o mesmo padrão de VOT do exemplo, o que gerou produções como [t]edo/ [d] ]edo e [k]ambá/ [̊̊]ambá para as palavras 'dedo' e 'gambá', respectivamente. Da mesma forma, porém em menor ocorrência, foram observados padrões de 'VOT negativo', quando eram esperadas produções de 'VOT zero'. São exemplos desse tipo de mudança de padrão as palavras [b]onte 'ponte', [d]emporal 'temporal' e [g]opo 'copo'. Um número mais elevado de dessonorizações do que de sonorizações também foi encontrado por Lara (2013), em sua dissertação de mestrado, que analisou as oclusivas bilabiais. O resultado apresentado por Lara (2013) reforça o conhecimento de que as dessonorizações ocorrem mais vezes do que as sonorizações no processo de transferência do hunsriqueano para o português.

0 presente trabalho analisa as transferências fonético-fonológicas do hunsriqueano para o português, no que diz respeito à sonoridade das oclusivas. Objetiva-se a partir da análise de leituras feitas em português: a) investigar a incidência da ocorrência de transferências em cada uma das oclusivas; b) comparar as transferências interlinguísticas encontradas com as regras de vozeamento do hunsriqueano, descritas por Altenhofen (1996), com relação à tonicidade das sílabas e, finalmente, c) verificar de que modo as diferentes dimensões (diatópica, diastrática, diageracional) sugeridas pelo modelo teórico da dialetologia pluridimensional (THUN, 1998, 2010) atuam na variação de sonoridade encontrada nos dados analisados.

\section{Referencial teórico}

\subsection{As oclusivas da língua de imigração hunsriqueana}

Altenhofen (1996) descreve as oclusivas do hunsriqueano com os seguintes fonemas: $/ \mathrm{p}^{\mathrm{h}} / \mathrm{,} / \mathrm{b} /, / \mathrm{t}^{\mathrm{h}} / \mathrm{,} / \mathrm{d} /, / \mathrm{k}^{\mathrm{h}} / \mathrm{e} / \stackrel{\mathrm{g}}{\mathrm{o}} /$ (ALTENHOFEN, 1996). A partir de um trabalho desenvolvido juntamente com o Altenhofen (GEWEHR-BORELLA; ALTENHOFEN, 2012), optou-se por representar os fonemas do hunsriqueano pelos símbolos mais genéricos, 
sendo os fonemas surdos representados pelos símbolos /p/, /t/ e /k/ e o sonoros pelos símbolos /b/, /d/ e /g/, reservando as formas apresentadas com aspiração e ensurdecimento para a realização fonética.

De acordo com Altenhofen (1996), as regras de vozeamento no hunsriqueano ocorrem da seguinte forma: a) em início e fim de palavra e em sílabas pretônica e tônica, ocorre, via de regra, oclusivas com dessonorização, chamadas de Halbfortes $^{3}$ (semisurdas), representadas pelo diacrítico 'bolinha', tendo um ensurdecimento parcial ou completo, como na pronúncia da palavra Butter 'manteiga', pronunciada como ['budə] ou ['pudə]; b) em sílaba postônica e intervocálica, ocorre normalmente a sonorização, num processo de lenização4 (ALTENHOFEN, 1996). A palavra backen 'assar', do alemão padrão, por exemplo, é pronunciada como ['bagə], no hunsriqueano. Segundo o mesmo autor, a regra de vozeamento é, geralmente, facultativa. Com frequência, as oclusivas vozeadas podem variar com suas respectivas não vozeadas no mesmo idioleto. Por esta razão, Altenhofen coloca as oclusivas Halbfortes como unidades relevantes. A seguir, tem-se um quadro ${ }^{5}$ com o resumo das regras de vozeamento do hunsriqueano.

Quadro 1: Regras de vozeamento do hunsriqueano

\begin{tabular}{|c|c|c|c|c|}
\hline Posição na sílaba & $\begin{array}{c}\text { Sílaba pré-tônica e } \\
\text { início de palavra }\end{array}$ & Sílaba tônica & $\begin{array}{c}\text { Sílaba pós- } \\
\text { tônica }\end{array}$ & $\begin{array}{c}\text { Fim de } \\
\text { palavra }\end{array}$ \\
\hline Processo & dessonorização & dessonorização & sonorização & dessonorização \\
\hline $\begin{array}{c}\text { Exemplo: bedanken } \\
\text { 'agradecer' }\end{array}$ & $<$ be & dan & ke> & - \\
\hline $\begin{array}{c}\text { Pronúncia no } \\
\text { hunsriqueano }\end{array}$ & {$[\mathrm{b}]$} & {$[\mathrm{d}]$} & {$[\mathrm{g}]$} & - \\
\hline $\begin{array}{c}\text { Exemplo: } \\
\text { lang } \\
\text { 'longo' }\end{array}$ & - & - & - & $<$ lang> \\
\hline $\begin{array}{c}\text { Pronúncia no } \\
\text { hunsriqueano }\end{array}$ & - & - & - & {$[\stackrel{\mathrm{g}}{\mathrm{o}}]$} \\
\hline
\end{tabular}

\footnotetext{
${ }^{3}$ Fortis: (consoante) articulada, ou com tendência a ser articulada, com tensão muscular acentuada. Termo tradicionalmente usado para consoantes surdas em oposição a consoantes sonoras. Do Latim "fortis" 'forte" (MATHEWS, 1997). Como 'Halb' em alemão significa 'meio', poderíamos dizer que o termo significa uma oclusiva gradiente, às vezes manifestando-se como surda e às vezes, como sonora.

4 Lenização ou lenição: qualquer processo através do qual um som é concebido como sendo "enfraquecido". Ex.: Na história do espanhol, as oclusivas sonoras [b], [d], [g] tornaram-se fricativas entre vogais, a partir da redução do esforço da articulação. Maiores detalhes sobre esse processo, consultar Altenhofen (1996).

5 Padrão de vozeamento das oclusivas do hunsriqueano, seguindo Altenhofen (1996).
} 
As regras de dessonorização e sonorização observadas no hunsriqueano podem ser transferidas para a fala do português. Com isso, palavras como 'guri' e 'disse', onde [g] e [d] aparecem respectivamente em sílaba pretônica e tônica, podem ocorrer como [g̊]uri e [d] isse, tendo as oclusivas dessonorizadas. A palavra 'público', por outro lado, pode aparecer com o segmento / $/$ / sonorizado, ou seja, públi[g]o, tendo em vista que a oclusiva velar surda encontra-se em posição postônica.

Além das regras de dessonorização e sonorização, faz-se necessário lembrar os processos de hipercorreção que ocorrem na fala em português de falantes da língua de imigração estudada. Ocorrências como [b]ai, para a palavra 'pai', são frequentes em alguns falantes. Talvez por escutar tantas vezes a expressão “(...) não é com ' $p$ ' é com 'b", o falante venha a utilizar [b] no lugar da oclusiva bilabial surda [p].

\subsection{0 sistema de vozeamento do português e do hunsriqueano}

Compreender as diferenças existentes no vozeamento das oclusivas do hunsriqueano e do português faz-se necessário para entender por que alguns informantes apresentam transferências interlinguísticas. O vozeamento pode ser medido nas consoantes oclusivas de ambas as línguas a partir do Voice Onset Time (VOT).

O VOT é o período de surdez entre a soltura/explosão da consoante e o início da periodicidade de vozeamento do segmento seguinte (LISKER; ABRAMSON, 1964). Os padrões de vozeamento são caracterizados a partir de três categorias de VOT, conforme pode ser observado na Fig. 1.

Figura 1: Três tipos de VOT

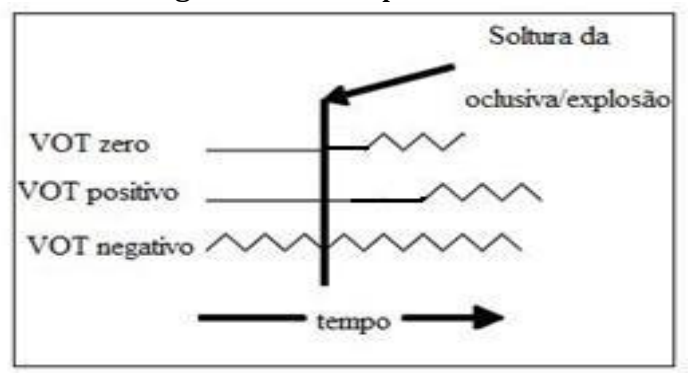

Fonte: GEWEHR-BORELLA (2010, p. 36) ${ }^{6}$

${ }^{6}$ Figura adaptada de Cohen (2004, p. 13). 
1a) Na categoria 'VOT zero' tem-se a soltura da oclusiva, representada pela barra vertical, seguida de um pequeno período de ensurdecimento, em torno de $+10 \mathrm{~ms}$, representado pela linha reta horizontal, e, logo após, o início da vibração das cordas vocais, na produção do segmento seguinte, ilustrada pela linha ondular. Estão enquadradas nesta categoria as oclusivas surdas /p/, /t/ e /k/ do português, por exemplo.

$2^{\text {a }}$ ) Na categoria 'VOT positivo' tem-se, ao invés de um pequeno período de ensurdecimento, um tempo maior de surdez, em torno de $+75 \mathrm{~ms}$, representado pela linha reta horizontal um pouco mais longa, e, logo após, da mesma forma, o início da vibração das cordas vocais, ilustrada pela linha ondular. Nesta categoria estão enquadradas as oclusivas surdas do inglês, do alemão padrão e do hunsriqueano, produzidas com aspiração.

$3^{\text {a }) ~ N a ~ c a t e g o r i a ~ ' V O T ~ n e g a t i v o ', ~ t a m b e ́ m ~ c h a m a d a ~ d e ~ p r e ́-v o z e a m e n t o, ~ t e m-s e ~ a ~}$ vibração das cordas vocais durante toda a produção da oclusiva, com o vozeamento já ocorrendo antes mesmo da soltura da oclusiva, em torno de $-100 \mathrm{~ms}$, na qual tem-se como exemplo as oclusivas sonoras /b/, /d/, /g/ do português.

Como os valores de VOT sofrem variações influenciadas por características como idade, velocidade da fala, dentre outras, não há consenso entre os pesquisadores a respeito dos seus valores médios para cada consoante. Entretanto, alguns estudiosos apresentam algumas classificações. Istre, citada por Klein (1999), por exemplo, afirma que os valores médios das oclusivas surdas do português são de 12ms para /p/; 18ms para /t/ e 38ms para /k/ (KLEIN, 1999, apud REIS; NOBRE-OLIVEIRA, 2008). As oclusivas surdas do português enquadram-se, portanto, dentro da categoria 'VOT zero'. Já as oclusivas sonoras, /b/, /d/ e /g/ são produzidas com pré-vozeamento, sendo classificadas, portanto, dentro da categoria 'VOT negativo'.

Quanto aos padrões de vozeamento das línguas de imigração alemãs, entre as quais se inclui o hunsriqueano, Braun (1996) demonstra que a grande maioria apresenta um período de surdez longo nas oclusivas /p/, /t/ e /k/, interpretadas como aspiradas, e um curto período de surdez nas oclusivas /b/, /d/ e /g/, concebidas como surdas não 
aspiradas. A autora apresenta alguns estudos que investigaram valores de VOT de dialetos da Alemanha. 0 hunsriqueano europeu falado em Koblenz e no Moselfrk, por exemplo, apresenta os respectivos valores de $\operatorname{VOT}(/ \mathrm{p} /=32, / \mathrm{t} /=37, / \mathrm{k} /=67, / \mathrm{b} /=11, / \mathrm{d} /=18, / \mathrm{g} /=$ 35) e $(/ \mathrm{p} /=38, / \mathrm{t} /=51.5, / \mathrm{k} /=68.5, / \mathrm{b} /=9, / \mathrm{d} /=10.5, / \mathrm{g} /=21.5)$ (BRAUN, 1996). Jessen e Ringen (2002) acrescentam que o VOT negativo, ou seja, o pré-vozeamento, é bastante raro nas línguas de imigração alemãs.

Em minha dissertação de mestrado (GEWEHR-BORELLA, 2010), analisei as oclusivas do hunsriqueano, em início de palavras, chegando às seguintes medidas de VOT: $/ \mathrm{p} /=\left[\mathrm{p}^{\mathrm{h}}\right] 87 \mathrm{~ms} ; / \mathrm{t} /=\left[\mathrm{t}^{\mathrm{h}}\right] 81 \mathrm{~ms}, / \mathrm{k} /=\left[\mathrm{k}^{\mathrm{h}}\right] 91 \mathrm{~ms}, / \mathrm{b} /=[\mathrm{p}] 27 \mathrm{~ms}, / \mathrm{d} /=[\mathrm{t}] 23 \mathrm{~ms}$, /g/= [k] 40ms, sendo, portanto, as oclusivas surdas classificadas dentro da categoria 'VOT positivo', por apresentarem aspiração, e as sonoras dentro da categoria 'VOT zero', por terem um período menor de surdez. Tem-se na Fig. 2 uma exemplificação.

Figura 2: Padrões de VOT do português e do hunsriqueano
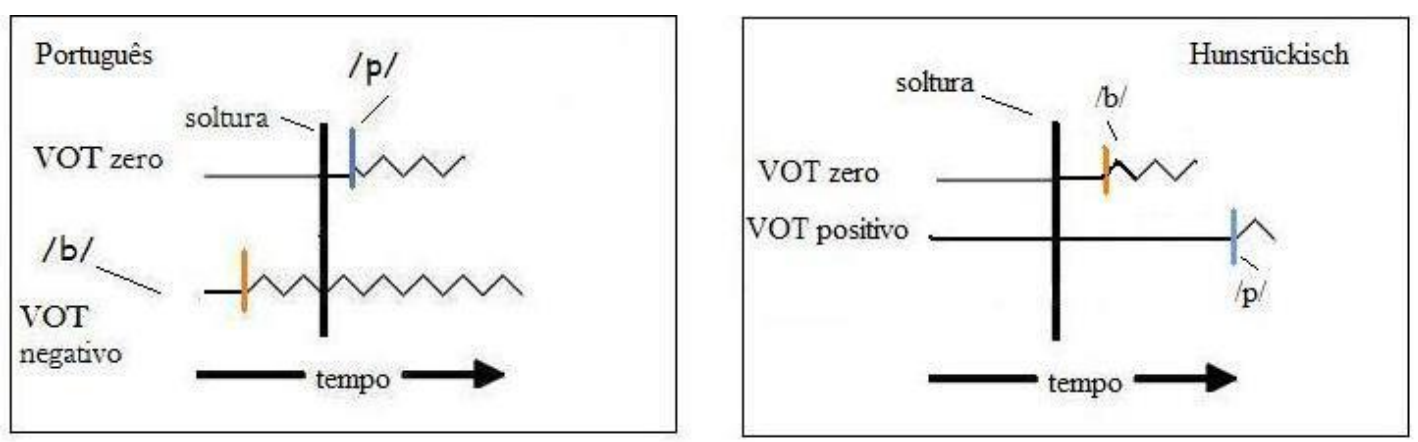

Fonte: GEWEHR-BORELLA (2010, p. 37)

Como pode ser observado, as oclusivas surdas do português, exemplificadas a partir do /p/ da figura da esquerda, são muito próximas às oclusivas sonoras do hunsriqueano, representadas pelo /b/ da figura da direita. Provavelmente, tal proximidade faz com que falantes de hunsriqueano apresentem em português produções como [p]anana ou [b]anana em vez de [b]anana, por exemplo.

\subsection{0 modelo teórico da dialetologia pluridimensional e relacional}

Diferentemente da dialetologia tradicional, que se restringe quase que exclusivamente à variação diatópica, deixando de abordar diferentes variáveis 
extralinguísticas, e da sociolinguística, que aborda diferentes dimensões em apenas um determinado espaço, a 'dialetologia pluridimensional e relacional' busca suprir as lacunas existentes nessas duas abordagens ao analisar diferentes variáveis extralinguísticas em diversos pontos de pesquisa (THUN, 1998, 2010).

Os modelos descritos são ilustrados na Fig. 3. Vê-se, à esquerda, o esquema da dialetologia tradicional, no qual apenas a fala de um determinado tipo de sujeito é estudada em diversos pontos de pesquisa (A, B, C... N). À direita, tem-se o modelo da sociolinguística, no qual várias variáveis $(\alpha, \beta \ldots)$ são analisadas em um único local de coleta. Abaixo, pode-se visualizar o modelo da dialetologia pluridimensional e relacional, uma estrutura tridimensional gerada a partir da combinação entre a superfície (dialetologia tradicional) e o eixo vertical (sociolinguística). Segundo Altenhofen (2006), tal modelo reagrega “(...) à dimensão diatópica horizontal as dimensões verticais reclamadas pela sociolinguística" (ALTENHOFEN, 2006, p. 163).

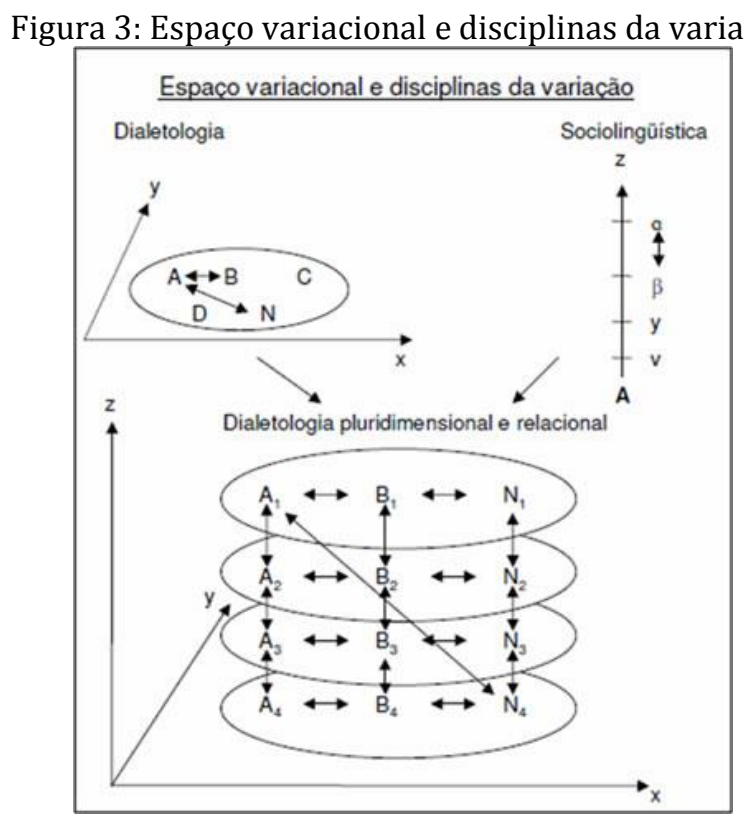

Fonte: Thun (1998, p. 705)

A partir do modelo proposto pela dialetologia pluridimensional e relacional é possível realizar análises não apenas horizontalmente (A1, B1... N1) e verticalmente (A1, A2,...) como também diagonalmente (A1, B2... N4). Essas análises diagonais possibilitam o contraste de diferentes tipos de dados (A1 $\leftrightarrow$ N4, por exemplo), o qual não seria possível na adoção de um dos modelos anteriormente expostos. 
0 foco de estudo da dialetologia pluridimensional não está mais na busca do registro do 'dialeto puro', enfatizado na dialetologia tradicional, nem dos socioletos, preferidos pela sociolinguística, mas reside, sim, na descrição contínua dos dialetos, ao comparar uma determinada variável na fala de informantes distintos.

O modelo proposto tem em seu título a expressão 'relacional' por apresentar as relações existentes entre o contato de línguas ou variedades linguísticas, primeiramente na pesquisa, e após na apresentação cartográfica dos dados. 0 questionário aplicado no decorrer das entrevistas fomenta inter-relações entre os informantes, a partir das quais surgem comentários metalinguísticos. Forma-se a partir de tais comentários uma outra relação, que liga o saber metalinguístico e o comportamento linguístico dos informantes (THUN, 1996). 0 modelo proposto também é 'pluridimensional' por incluir diversas dimensões de análise, dentre as quais destacam-se as utilizadas no presente estudo, sendo elas a dimensão diatópica (pontos de pesquisa), a diastrática (estratos sociais) e a diageracional (idade).

\section{Procedimentos metodológicos}

\subsection{Pontos de pesquisa}

Fazem parte do presente estudo seis dos 41 pontos de pesquisa do Projeto AlmaH: RS02 (Ivoti e Dois Irmãos), RS04 (Santa Maria do Herval), RS10 (Colinas), RS11 (Forquetinha e Lajeado), RS13 (Santa Cruz do Sul) e RS19 (Panambi).

\subsection{Informantes}

Em cada um dos pontos analisados, foram coletados, por entrevistadores do Projeto Alma-H, dados de fala de informantes de quatro grupos sociais (CaGII, CaGI, CbGII e CbGI), equivalentes aos parâmetros das dimensões diastrática e diageracional, conforme o Quadro 2. Todos os informantes são bilíngues hunsriqueano-português, com grande proficiência em hunsriqueano, nasceram na localidade ou vivem $3 / 4$ da vida na localidade, obrigatoriamente nos últimos cinco anos. Em cada um dos grupos, foi entrevistado pelo menos um informante, tendo cada ponto, portanto, no mínimo quatro entrevistas. 
Quadro 2: Informantes em cada um dos pontos (siglas explicativas)

\begin{tabular}{|c|c|c|c|}
\hline \multirow[b]{2}{*}{ CaGll } & \multirow[b]{2}{*}{$\mathrm{CaGl}$} & $\mathbf{C a}=$ Classe alta & $\begin{array}{l}\text { Informantes com escolaridade superior e } \\
\text { ocupação profissional livre/autônoma }\end{array}$ \\
\hline & & $\mathbf{C b}=$ Classe baixa & $\begin{array}{l}\text { Informantes com escolaridade básica (analfabeto } \\
\text { até } 2^{\circ} \text { grau incompleto) e ocupação profissional } \\
\text { agricultor ou empregado que não exija o uso da } \\
\text { escrita }\end{array}$ \\
\hline \multirow{2}{*}{ CbGII } & \multirow{2}{*}{$\mathrm{CbGl}$} & GI = Geração I & Informante de 18 a 36 anos \\
\hline & & GII = Geração II & Informante acima de 55 anos \\
\hline
\end{tabular}

Fonte: Gewehr-Borella e Altenhofen (2012, p. 9)

\subsection{Dados analisados}

São utilizadas para a análise todas as oclusivas da 'Parábola do Filho Pródigo' (Anexo 1) em português, totalizando 367 oclusivas por leitura, sendo: $64<\mathrm{P}>, 17<\mathrm{B}>$, $97<\mathrm{T}>, 97<\mathrm{D}>, 66<\mathrm{C} / \mathrm{QU}>$ e $26<\mathrm{G}>$, conforme pode ser observado no Anexo 2.

\section{Análise dos dados}

Num total de 9168 oclusivas analisadas, apenas 180 (1,96\%) apresentaram padrões distintos do português, sendo 151 dessonorizações $(83,89 \%)$ e 29 sonorizações (16,11\%). Nas figuras apresentadas a seguir, ilustram-se as produções da palavra 'gastou', produzidas por dois informantes distintos, sendo a primeira realizada dentro dos padrões do português (Fig. 4), isto é, com pré-vozeamento, e a segunda fora dos padrões (Fig. 5), tendo em vista a dessonorização apresentada.

Figura 4: Produção da palavra 'gastou', com pré-vozeamento, realizada por informante pertencente ao grupo RS02 CaGI

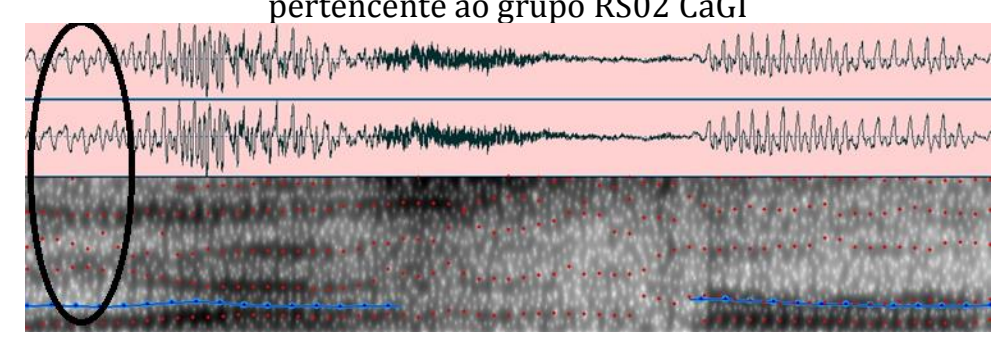


Figura 5: Produção da palavra 'gastou', sem pré-vozeamento, realizada por informante pertencente ao grupo RS02 CaGII

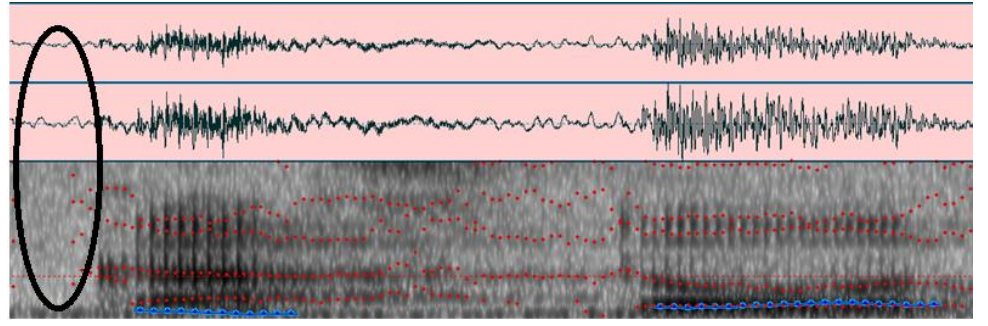

\subsection{Incidência da ocorrência de transferências em cada uma das oclusivas}

Conforme pode ser observado na Tab. 1, a oclusiva que apresentou maior ocorrência de padrões distintos do português foi a oclusiva bilabial sonora [b], seguida da oclusiva velar sonora [g] e da oclusiva alveolar sonora [d]. As oclusivas surdas, por sua vez, apresentaram poucos processos de sonorização, ficando todas com menos de $1 \%$ de transferência.

Tabela 1 - Incidência de transferência em cada oclusiva

\begin{tabular}{ccccccc}
\hline & [p] & [t] & [k] & [b] & [d] & [g] \\
\hline RS02 & $0,66 \%$ & $0,43 \%$ & $0,64 \%$ & $5,19 \%$ & $3,64 \%$ & $10,40 \%$ \\
RS04 & $1,17 \%$ & $0 \%$ & $1,17 \%$ & $6,97 \%$ & $4,42 \%$ & $4,61 \%$ \\
RS10 & $0,24 \%$ & $0 \%$ & $0,23 \%$ & $9,61 \%$ & $1,77 \%$ & $4,29 \%$ \\
RS11 & $0,42 \%$ & $0,29 \%$ & $1,61 \%$ & $11,29 \%$ & $3,97 \%$ & $9,37 \%$ \\
RS13 & $0,78 \%$ & $2,34 \%$ & $0 \%$ & $15,15 \%$ & $4,46 \%$ & $13,72 \%$ \\
RS19 & $0 \%$ & $0 \%$ & $0 \%$ & $0 \%$ & $0 \%$ & $0 \%$ \\
Total & $0,54 \%$ & $0,51 \%$ & $0,60 \%$ & $\mathbf{8 , 0 3 \%}$ & $\mathbf{3 , 0 4 \%}$ & $\mathbf{7 , 0 6 \%}$ \\
\hline
\end{tabular}

Dentre as palavras que mais sofreram processos de dessonorização destacam-se as palavras 'bens (l. 03)', 'gastou (l. 05)', 'dava (l. 10)', 'braços (l. 17)' e 'banquete (l. 21)', todas sendo dessonorizadas por seis informantes distintos.

\subsection{Transferências versus regras de vozeamento do hunsriqueano}

Dos 180 padrões de sonoridade distintos do português encontrados, 149 $(82,78 \%)$ seguiram as regras do hunsriqueano, discutidas por Altenhofen (1996), isto é, apresentando dessonorizações em sílabas pretônica e tônica e sonorização em sílaba 
postônica (Tab. 2). Já 17,22\% (31 dados) não seguiram as regras de vozeamento do hunsriqueano, por apresentarem dessonorização em sílaba tônica e sonorizações em sílaba pretônica e tônica.

Tabela 2 - Transferência versus regra de vozeamento do hunsriqueano

\begin{tabular}{l|ccc|ccc}
\hline & \multicolumn{3}{|c|}{ Dessonorizações } & \multicolumn{3}{c}{ Sonorizações } \\
\hline & Pretônica & Tônica & Postônica & Pretônica & Tônica & Postônica \\
RS02 & 11 & 21 & 2 & 1 & 4 & 1 \\
RS04 & 7 & 11 & 0 & 2 & 2 & 0 \\
RS10 & 11 & 16 & 1 & 0 & 2 & 0 \\
RS11 & 15 & 15 & 0 & 3 & 3 & 0 \\
RS13 & 15 & 25 & 1 & 0 & 10 & 1 \\
RS19 & 0 & 0 & 0 & 0 & 0 & 0 \\
& $\mathbf{5 9}$ & $\mathbf{8 8}$ & 4 & 6 & 21 & $\mathbf{2}$ \\
\hline
\end{tabular}

\subsection{Dimensões da dialetologia pluridimensional versus variação de sonoridade}

A Fig. 6 foi criada a partir dos índices apresentados na tabela a seguir:

Tabela 3 - Índices de transferência na cruz de análise

\begin{tabular}{lcccc}
\hline & CaGI & CaGII & CbGI & CbGII \\
\hline RS02 & $0 \%$ & $4,10 \%$ & $0,13 \%$ & $\mathbf{8 , 7 5 \%}$ \\
RS04 & $0 \%$ & $1,36 \%$ & $0,61 \%$ & $\mathbf{2 1 , 0 5 \%}$ \\
RS10 & $0 \%$ & $4,37 \%$ & $\mathbf{0 , 6 8 \%}$ & $0,27 \%$ \\
RS11 & $0 \%$ & $1,19 \%$ & $0,55 \%$ & $\mathbf{1 0 , 6 0 \%}$ \\
RS13 & $0 \%$ & $0 \%$ & $0 \%$ & $\mathbf{1 4 , 4 4 \%}$ \\
RS19 & $0 \%$ & $0 \%$ & $0 \%$ & $0 \%$ \\
\hline
\end{tabular}

Com relação à dimensão diageracional (idade), percebe-se que os informantes da segunda geração (GII) produzem mais transferências do que os informantes da primeira geração (GI), em todos os grupos que apresentam diferença (Fig. 6).

A dimensão diastrática (classe social) também se mostra relevante, tendo em vista a presença de um maior número de transferências da classe baixa ( $\mathrm{Cb}$ ) em comparação com a classe alta (Ca), em quatro dos seis grupos analisados.

Por fim, quanto à dimensão diatópica, chama-nos a atenção a ausência total de transferência no ponto RS19, bastante urbanizado e com um médio índice populacional (em torno de 40 mil habitantes), juntamente com o maior número de padrões diferenciados no ponto RS04, mais rural e com baixo índice populacional (em torno de seis mil habitantes). 
Figura 6: Representação dos dados analisados a partir das dimensões diatópica, diastrática e diageracional

\begin{tabular}{|c|c|c|c|c|c|c|c|}
\hline CaGII & CaGI & \multicolumn{2}{|c|}{ RS02 } & \multicolumn{2}{|c|}{ RS04 } & \multicolumn{2}{|c|}{ RS10 } \\
\hline CbGII & $\mathrm{CbGI}$ & () & 0 & 0 & 0 & () & 0 \\
\hline & 1501 ate $21.05 \%$ & & & & $\checkmark$ & & \\
\hline () & 6,01 até $15 \%$ & \multicolumn{2}{|c|}{ RSII } & \multicolumn{2}{|c|}{ RS13 } & \multicolumn{2}{|c|}{ RS19 } \\
\hline (1) & 2,01 até $6,0 \%$ & - & 0 & 0 & 0 & 0 & 0 \\
\hline () & 0,01 até $2,0 \%$ & & & & & & \\
\hline 0 & $0 \%$ & $\boldsymbol{v}$ & () & $\bullet$ & 0 & O & 0 \\
\hline
\end{tabular}

\section{Considerações finais}

Buscou-se no presente artigo analisar transferências fonético-fonológicas do hunsriqueano para o português, relativas à sonoridade das oclusivas. Objetivou-se com as análises realizadas: a) investigar a incidência da ocorrência de transferências em cada uma das oclusivas; b) comparar as transferências interlinguísticas encontradas com as regras de vozeamento do hunsriqueano, com relação à tonicidade das sílabas e, finalmente, c) verificar de que modo diferentes dimensões sugeridas pelo modelo teórico da dialetologia pluridimensional (THUN, 1998, 2010) atuariam na variação de sonoridade dos dados analisados.

Primeiramente é preciso mencionar que o número de transferências encontrado ficou abaixo do esperado, ocorrendo em apenas 1,96\% dos dados analisados. No entanto, ressalta-se que outras transferências da língua de imigração para o português foram encontradas, inclusive em maior número do que as relativas às dessonorizações/sonorizações de oclusivas. Um exemplo de transferência bastante realizada diz respeito à utilização do tepe em palavras com [r]iqueza e te[r]a, o que demonstra ainda uma forte influência do hunsriqueano na fala do português.

Quanto aos processos de transferência analisados, foram encontrados mais processos de dessonorizações $(83,89 \%)$ do que sonorizações $(16,11 \%)$, o que condiz 
com o padrão de vozeamento do hunsriqueano, o qual apresenta um número bem mais elevado de dessonorizações em seu sistema.

Com relação ao tipo de oclusiva, foram encontradas mais transferências na oclusiva bilabial sonora, seguida da oclusiva velar sonora e da alveolar sonora, tendo as oclusivas surdas poucos processos de transferência.

As regras de vozeamento do hunsriqueano, relativas à tonicidade silábica, foram transferidas para a leitura do português em $82,78 \%$ dos dados. Cremos que os dados não atingidos pelas regras de vozeamento do hunsriqueano sejam processos de hipercorreção, aos quais o falante recorre em decorrência de sua insegurança quanto ao sistema de vozeamento do português.

Uma análise baseada no modelo teórico da dialetologia pluridimensional fez-nos observar diferenças diageracionais, diastráticas e diatópicas, tendo a segunda geração (GII) mais transferências que a primeira (GI) em todos os grupos analisados, a classe alta um menor número de transferências do que a classe baixa ( $\mathrm{Cb}$ ), em quatro dos seis grupos analisados, e os pontos com mais (RS04) e menos (RS19) processos de dessonorização/sonorização diferenças com relação ao grau de ruralidade/urbanização e índice populacional. Percebe-se que tanto o aumento da escolaridade quanto um maior contato com meios de comunicação, como a televisão e a internet, atuam na redução do número de transferências, em razão da grande exposição dos falantes aos padrões de vozeamento do português.

Ressalta-se, por fim, que os resultados apresentados permitem um melhor entendimento dos processos de transferência interlinguística entre o hunsriqueano e o português, o que contribui para a descrição da variedade do português falada nas regiões pesquisadas.

\section{Referências}

ALTENHOFEN, Cléo Vilson. Hunsrückisch in Rio Grande do Sul: Ein Beitrag zur Beschreibung einer deutschbrasilianischen Dialektvarietät im Kontakt mit dem Portugiesischen. Stuttgart: Franz Steiner Verlag, 1996.

Interfaces entre dialetologia e história. In: MOTA, Jacyra; CARDOSO, Suzana Alice Marcelino (Org.). Documentos 2: Projeto Atlas Lingüístico do Brasil. Salvador: Quarteto, 2006. p. 159-185. 
Migrações e contatos linguísticos na perspectiva da geolinguística pluridimensional e contatual. Revista de Letras Norte@mentos, v. 6, p. 19-43, 2013.

ALTENHOFEN, Cléo Vilson. et al. Fundamentos para uma escrita do Hunsrückisch falado no sul do Brasil. In: DREHER, Martin; KUNZ, Jaqueline Anschau.; MUGGE, Miquéias Henrique (Org.). Imigração e relações interétcnicas. XVII SIMPÓSIO DE HISTÓRIA DA IMIGRAÇÃO E COLONIZAÇÃO. 2006. São Leopoldo: Oikos, 2008, p. 1199-1216. 1 CD ROM.

BRAUN, Angelika. Zur regionalen Distribution von VOT in Deutschen. In: . (Hg.). Untersuchungen zu Stimme und Sprache: Papers on Speech and Voice, Germany, 1996, p. 19-32.

COHEN, Gustavo Vargas. The VOT Dimension: a bi-directional experiment with English and Brasilian-Portuguese stops. 2004. 70 f. Dissertação (Mestrado em Letras/Inglês e Literatura correspondente) - Faculdade de Letras. Universidade Federal de Santa Catarina: Florianópolis, 2004.

GEWEHR-BORELLA, Sabrina. A influência da fala bilíngue Hunsrückisch- Português brasileiro na escrita de crianças brasileiras em séries iniciais. 2010. 205 f. Dissertação (Mestrado em Letras/Linguística Aplicada)- Pós-Graduação em Letras. Universidade Católica de Pelotas, Pelotas, 2010.

GEWEHR-BORELLA, Sabrina; ALTENHOFEN, Cléo Vilson. Macroanálise pluridimensional da variação de consoantes oclusivas do português por falantes de hunsriqueano. In: IV SEMINÁRIO INTERNACIONAL DE FONOLOGIA, 2012, Porto Alegre, Anais... Porto Alegre, RS: Upplay, 2012. 1 CD ROM.

JESSEN, Michael; RINGEN, Catherine. Laryngel features in German Phonology. Phonology. n. 19, p. 189-218, 2002.

LARA, Claudia Camila. Variação fonológica, redes e práticas sociais numa comunidade bilíngue português-alemão do Brasil meridional. 2013. 105 f. Dissertação (Mestrado em Letras/Fonologia e morfologia) - Pós-Graduação em Letras. Universidade Federal do Rio Grande do Sul, Porto Alegre, 2013.

LISKER, Leigh; ABRAMSON, Arthur. A Cross-Language Study of Voicing in Initial Stops: Acoustical Measurements, Word, 20, 1964, p. 384-422.

MATHEWS, Peter. The Concise Oxford Dictionary of Linguistics. United States: Oxford University Press, 1997.

REIS, Mara; NOBRE-OLIVEIRA, Denize (2008) Effects of perceptual training on the identification and production of English voiceless plosives aspiration by Brazilian EFL learners. In: RAUBER, Andréia Schurt; BAPTISTA, Barbara. Oughton; WATKINS, Michael Alan (Ed.). New Sounds 2008: PRECEEDINGS OF THE FIFTH INTERNATIONAL SYMPOSIUM ON THE ACQUISITION OF SECOND LANGUAGE SPEECH. 2008. Anais... Florianópolis, SC: UFSC, 2008. p. 398-407. 
THUN, Harald. Movilidad demográfica y dimensión topodinámica. Los montevideanos en Rivera. In: RADTKE, Edgar; THUN, Harald (Org.). Neue Wege der romanischen Geolinguistik: Akten des Symposiums zur empirischen Dialektologie. Kiel : WestenseeVerl., 1996. p. 210-269.

- La geolingüística como linguística variacional general (com ejemplos del Atlas lingüístico Diatópico y Diastrático del Uruguay. In: InTERNATIONAL CONGRESS OF ROMANCE Linguistics AND PHILOLOGY (21. : 1995 : Palermo). Atti del XXI Congresso Internazionale di Linguistica e Filologia Romanza. Org. Giovanni Ruffino. Tübingen: Niemeyer, 1998. v. 5, p. 701-729, incluindo resumo dos tópicos principais da seção 5, p. 787-789.

. Pluridimensional cartography. In: LAMELI, Alfred; KEHREIN, Roland; RABANUS, Stefan (Eds.). Language mapping. Berlin: de Gruyter Mouton, 2010. p. 506-523. 
ANEXO 1 - Parábola do filho pródigo (Lucas, 14,15)

Jesus disse também: "Um certo homem tinha dois filhos. 0 mais novo pediu ao pai: "Pai, tenho a idéia de ganhar experiência na vida. Dá-me a parte da herança que me pertence." o pai, decepcionado, repartiu os seus bens entre os dois filhos. Poucos dias depois, o mais novo liquidou o que era dele e partiu para uma terra muito distante, onde gastou todo o dinheiro numa vida desregrada.

Quando já não tinha dinheiro, e como houve muita fome e árduo sofrimento naquela região, começou a padecer de extrema necessidade. Foi pedir trabalho a alguém da região. 0 homem mandou-o para os seus campos guardar e cuidar dos porcos. Desejava encher o estômago mesmo com uma espécie de bolotas que os porcos e os cães comiam, mas ninguém lhas dava. Foi então que, numa noite, ele caiu em si e, inquieto no seu exílio, pensou: "Eu mínguo a riqueza do meu pai. Perdi o juízo! E tantos trabalhadores do meu pai têm quanta comida querem. Nunca há penúria, e eu estou parado aqui doente no meu lençol e a morrer de fome! Amanhã vou mas é ter com o meu pai e digo-lhe: "Pai, pequei contra o céu e contra ti. Já não mereço ser chamado teu filho, mas aceita-me como um de teus trabalhadores."

Levantou-se e voltou para o pai. [Mas] ainda ele vinha longe de casa e já o pai o tinha visto. Cheio de ternura, o bom pai correu para ele, apertou-o nos braços e cobriu-o de beijos. O filho disse-lhe então: "Pai, pequei contra Deus e contra ti. Já nem mereço ser chamado teu filho." Mas o pai disse logo aos empregados: "Tragam depressa a melhor roupa e vistam-lho. Ponham-lhe também um anel no dedo e calcem-lhe sandálias nos pés. Tragam o bezerro mais gordo que criamos e matem-no. Vamos fazer um banquete no pátio. Porque este meu filho estava morto e voltou a viver; estava perdido e apareceu." E começaram com a festa.

Ora, o filho mais velho estava no campo. Ao regressar, aproximando-se da casa, ouviu a música e as danças. Chamou um dos empregados e perguntou-lhe admirado o que era aquilo. E o empregado disse-lhe: "Foi o teu irmão que voltou, e por ordem do pai matamos o bezerro mais gordo, por ele ter chegado são e salvo." Ao ouvir isso, ficou indignado e mui amolado e nem queria entrar. Mas o pai saiu para o convencer.

Mas o filho maior respondeu: "Sirvo-te há tantos anos, sem nunca ter desobedecido às tuas ordens, e não me deste sequer um cabrito para fazer uma festa com os meus amigos. Isso me dói. Vem agora este teu filho, que desperdiçou o teu dinheiro com mulheres de má vida, e nós matamos o bezerro mais gordo. Não quero que míngues mais a tua riqueza nem a minha com este infeliz."

O pai disse-lhe com voz tênue: "Meu filho, tu estás sempre comigo, e tudo o que eu tenho é teu. Mas era preciso fazermos uma festa e alegrarmo-nos, porque o teu irmão estava morto e voltou a viver, estava perdido e apareceu." 
ANEXO 2 - Oclusivas analisadas

\begin{tabular}{|l|l|l|l|l|l|}
\hline \multicolumn{9}{|c|}{ Oclusivas bilabiais (81) } \\
\hline \multicolumn{1}{|c|}{$\begin{array}{c}\text { pré-tônica } \\
(28)\end{array}$} & \multicolumn{1}{|c|}{$\begin{array}{c}\text { tônica } \\
(32)\end{array}$} & $\begin{array}{c}\text { pós-tônica } \\
(4)\end{array}$ & $\begin{array}{c}\text { pré-tônica } \\
(8)\end{array}$ & $\begin{array}{c}\text { tônica } \\
(9)\end{array}$ & $\begin{array}{c}\text { pós-tônica } \\
(0)\end{array}$ \\
\hline Pediu & pai (15) & campos & bolotas & também (2) & ------------- \\
\hline experiência & parte & roupa & trabalhadores (2) & bens & \\
\hline pertence & Poucos & campo & bezerro (3) & trabalho & \\
\hline repartiu & depois & sempre & banquete & bom & \\
\hline Partiu & para (5) & & desobedecido & braços & \\
\hline padecer & porcos (2) & & & cobriu-o & \\
\hline Pedir & Espécie & & & beijos & \\
\hline pensou & depressa & & & cabrito & \\
\hline Perdi & ponham-lhe & & & & \\
\hline penúria & Pés & & & & \\
\hline parado & Pátio & & & & \\
\hline pequei (2) & por (2) & & & & \\
\hline apertou-o & & & & & \\
\hline empregados (2) & & & & & \\
\hline porque (2) & & & & & \\
\hline perdido (2) & & & & & \\
\hline apareceu (2) & & & & & \\
\hline aproximando-se & & & & & \\
\hline perguntou-lhe & & & & & \\
\hline empregado & & & & & \\
\hline respondeu & & & & & \\
\hline desperdiçou & & & & & \\
\hline preciso & & & & & \\
\hline
\end{tabular}

\begin{tabular}{|c|c|c|c|c|c|}
\hline \multicolumn{6}{|c|}{ Oclusivas alveolares/dentais (194) } \\
\hline \multicolumn{3}{|c|}{$<\mathrm{T}>(97)$} & \multicolumn{3}{|c|}{$<\mathrm{D}>(97)$} \\
\hline $\begin{array}{l}\text { pré-tônica } \\
(6)\end{array}$ & $\begin{array}{c}\text { tônica } \\
(56)\end{array}$ & $\begin{array}{c}\text { pós-tônica } \\
\text { (35) }\end{array}$ & $\begin{array}{c}\text { pré-tônica } \\
(16)\end{array}$ & $\begin{array}{l}\text { tônica } \\
(49)\end{array}$ & $\begin{array}{c}\text { pós-tônica } \\
(32)\end{array}$ \\
\hline também (2) & $\operatorname{tinha(3)}$ & certo & decepcionado & disse (2) & vida (3) \\
\hline trabalho & tenho(2) & parte & depois & Dois(2) & decepcionado \\
\hline $\begin{array}{l}\text { trabalhadores } \\
\text { (2) }\end{array}$ & pertence & entre & distante & pediu & onde \\
\hline \multirow[t]{16}{*}{ ternura } & repartiu & muito & dinheiro (3) & ideia & todo \\
\hline & partiu & distante & desregrada & de (9) & desregrada \\
\hline & terra & muita & padecer & dá-me & quando \\
\hline & distante & sofrimento & desejava & da (3) & árduo \\
\hline & gastou & bolotas & doente & dias & necessidade \\
\hline & todo & noite & depressa & liquidou & comida \\
\hline & extrema & inquieto & indignado & dele & parado \\
\hline & estômago & tantos (2) & desobedecido & necessidade & chamado (2) \\
\hline & então (2) & quanta & desperdiçou & pedir & empregados (2) \\
\hline & tantos (2) & doente & & mandou-o & dedo \\
\hline & têm & contra (4) & & guardar & gordo (3) \\
\hline & Estou & aceita-me & & cuidar & perdido (2) \\
\hline & $\operatorname{ter}(3)$ & visto & & dava & aproximando-se \\
\hline & ti (2) & vistam-lho & & do (3) & admirado \\
\hline & teu (7) & matem-no & & perdi & empregado \\
\hline & Teus & banquete & & trabalhadores & ordem \\
\hline
\end{tabular}




\begin{tabular}{|l|l|l|l|l|l|}
\hline & & & $(2)$ & \\
\hline & levantou-se & pátio & & digo-lhe & chegado \\
\hline & voltou (4) & este (3) & & disse-lhe (3) & indignado \\
\hline & apertou-o & morto (2) & & deus & amolado \\
\hline & tragam (2) & festa (3) & & dedo & desobedecido \\
\hline & estava (5) & sirvo-te & & sandálias & ordens \\
\hline & $\begin{array}{l}\text { perguntou- } \\
\text { lhe }\end{array}$ & deste & & perdido (2) & tudo \\
\hline & matamos (2) & cabrito & & danças & \\
\hline & entrar & & Dos (2) & \\
\hline & Tuas & & respondeu & \\
\hline & Tua & & deste & \\
\hline & Tênue & & dói & \\
\hline & Tu & & & & \\
\hline & Estás & & & & \\
\hline Tudo & & & & \\
\hline
\end{tabular}

\begin{tabular}{|l|l|l|l|l|l|}
\hline \multicolumn{7}{|c|}{ Oclusivas velares (92) } \\
\hline \multicolumn{1}{|c|}{$\begin{array}{c}\text { pré-tônica } \\
(15)\end{array}$} & \multicolumn{1}{|c|}{$\begin{array}{c}\text { tônica } \\
(45)\end{array}$} & $\begin{array}{c}\text { pós-tônica } \\
(6)\end{array}$ & $\begin{array}{c}\text { pré-tônica } \\
(5)\end{array}$ & $\begin{array}{c}\text { tônica } \\
(12)\end{array}$ & $\begin{array}{c}\text { pós-tônica } \\
(9)\end{array}$ \\
\hline liquidou & que (10) & poucos & ganhar & desregrada & estômago \\
\hline começou & quando & porcos (2) & gastou & alguém & mínguo \\
\hline cuidar & como (2) & nunca (2) & guardar & ninguém & digo-lhe \\
\hline comiam & naquela & música & regressar & empregados (2) & logo \\
\hline caiu & campos & & $\begin{array}{l}\text { perguntou- } \\
\text { lhe }\end{array}$ & gordo (3) & tragam (2) \\
\hline inquieto & com (7) & & & empregado & amigos \\
\hline comida & cães & & & chegado & míngues \\
\hline correu & riqueza (2) & & & agora & comigo \\
\hline cobriu-o & quanta & & & alegrarmo-nos & \\
\hline criamos & querem & & & & \\
\hline começaram & aqui & & & & \\
\hline queria & pequei (2) & & & & \\
\hline convencer & contra (4) & & & & \\
\hline cabrito & casa (2) & & & & \\
\hline comigo & calcem-lhe & & & & \\
\hline & banquete & & & & \\
\hline & porque (2) & & & & \\
\hline & campo & & & & \\
\hline & aquilo & & & & \\
\hline & ficou & & & & \\
\hline & sequer & & & & \\
\hline & quero & & & & \\
\hline
\end{tabular}

Recebido em junho de 2014.

Aceito em novembro de 2014. 